\title{
0 Império de Santo Elesbão na cidade do Rio de Janeiro, no século XVIII
}

\author{
Mariza de Carvalho Soares
}

Les Danhomênous, les Mahinous et les Ayonous ont tous des yeux noirs. Quant aux Blancs, ils les ont ou noirs, ou couleur de feuille sèche, ou couleur de feuille verte comme ceux de chats. C'est sans doute pour cela que ces Troncsblancs ne voient pas les choses sous le même aspects que nous. Paul Hazoumé. Doguicimi.

\section{Introdução}

o século XVIII o tráfico atlântico contribui para a nova configuração
tanto dos reinos africanos quanto das colônias americanas nele envolvidas. Embora essa afirmação possa parecer óbvia, poucos têm sido os historiadores interessados em conhecer de modo diferenciado o destino da geração de escravos efetivamente traficada para fora da África e em entender o modo como ela enfrenta a experiência do cativeiro. Um conjunto de trabalhos de historiadores africanistas produzidos a partir dos anos de 1980, abre novas perspectivas de análise para a escravidão, despertando o interesse pelo estudo dos povos africanos e do tráfico de escravos entre a África e as Américas. ${ }^{1}$ Mas essas leituras exigem alguns cuidados. Ao incorporar a história da África aos estudos sobre escravidão é necessário levar em conta que o historiador das Américas faz uso da historiografia africana de um ponto de vista diferente daqueles que trabalham com a história da África e da escravidão no continente africano. O historiador da escravidão nas Américas está lidando com indivíduos e segmentos de grupos africanos que encontram na reorganização étnica uma alternativa para enfrentar o cativeiro. A especificidade da situação dos africanos escravizados exige o reconhecimento

\footnotetext{
*Agradeço ao Professor Paul Lovejoy, ao Embaixador Alberto da Costa e Silva e ao Professor
} A. J. R. Russell-Wood por seus comentários à primeira versão desse artigo.

Topoi, Rio de Janeiro, mar. 2002, pp. 59-83. 
não apenas do seu passado africano, mas do impacto do tráfico e das novas condições por eles encontradas no cotidiano da escravidão. ${ }^{2}$

Partindo da idéia de que o tráfico e os rearranjos que dele decorrem reconfiguram a composição dos segmentos dos grupos étnicos africanos escravizados e que tal perspectiva é imprescindível à análise da escravidão nas Américas, quero destacar duas questôes que servirão de eixo condutor para esse texto.

A primeira é o uso recorrente das chamadas "nações" (mina, angola, moçambique, benguela) como mecanismo de identificação e organização dos africanos em toda a extensão das Américas. Mesmo tendo um componente étnico e também cultural, as nações - aqui entendidas como um sistema classificatório que emerge do universo do tráfico atlântico redefinem as fronteiras entre os grupos étnicos através da formação de unidades mais inclusivas, por mim denominadas "grupos de procedência". A noção de grupo de procedência se inspira nos trabalhos do antropólogo Fredrik Barth que aponta a existência de sistemas sociais abrangentes onde interagem indivíduos de diferentes grupos étnicos. Seguindo essa mesma orientação teórica, o historiador Paul Lovejoy alerta para o fato de que, como resultado da migração forçada da escravidão, as identificações étnicas podem se tornar mais inclusivas, fazendo emergir uma esfera de solidariedade entre diferentes grupos étnicos, mesmo quando não existem condições previamente determinadas para isso. ${ }^{3}$ Uma vez instalados no Novo Mundo os escravos se agrupam em torno das ditas naçôes. Inicialmente uma identidade atribuída, a nação acaba sendo incorporada pelos grupos e servindo, de forma alternativa ou combinada, como ponto de partida para o reforço de antigas fronteiras étnicas ou para o estabelecimento de novas configurações identitárias. Assim, o grupo de procedência denominado mina no Rio de Janeiro não tem necessariamente a mesma composição étnica encontrada na Bahia, em Pernambuco ou no Maranhão. Também o que é designado mina no Rio de Janeiro no século XVIII difere do que, na mesma cidade, é mina, no século XIX. Tais diferenças decorrem das populações traficadas e dos arranjos no interior de cada nação, em cada cidade, época e situação. Por isso mais que etnias (no sentido de grupos originais ou de traços culturais primordiais) considero estar tratando aqui de um conjunto de configurações étnicas em permanente processo de transformação. 
A segunda questão a ser destacada é o modo como os segmentos dos grupos étnicos que reconstroem sua identidade conseguem, enquanto grupo, reverter a seu favor as regras da escravidão. A partir dos anos de 1980, novas pesquisas sobre escravidão no Brasil abrem caminho para uma melhor compreensão das formas de organização da população escrava. ${ }^{4} \mathrm{~A}$ leitura desses trabalhos mostra que a sociedade escravista apresenta determinadas regras e limites para a vida da população escrava e que os indivíduos aprendem a se mover no interior dessas regras, de modo a criar alternativas de convivência ou contestação, de acordo com as condições particulares, que cada caso oferece. A existência já na Península Ibérica de irmandades de homens brancos nas quais é exigida a pureza de sangue faz surgirem, ainda em Portugal, irmandades "de Homens Pretos". 5 Assim é que, tanto em Portugal - para onde vão os primeiros escravos africanos ainda no século XV — quanto no Brasil, as irmandades são a primeira e principal forma institucionalizada de organização dos negros africanos e de seus descendentes escravos, forros e livres. ${ }^{6} \mathrm{~A}$ primeira irmandade de homens pretos de que se tem notícia em Portugal é a Irmandade de NS do Rosário do Mosteiro de São Domingos, criada em Lisboa no ano de 1460. Lendo com cuidado o compromisso de 1565 é possível perceber que, nesta data, aí estão reunidos pretos, mouriscos brancos, mulatos e índios, mas só os pretos nãoescravos podem assumir cargos na hierarquia da Irmandade. ${ }^{7}$ Uma vez instaladas na colônia do Brasil, as irmandades de pretos se organizam regulamentando a entrada de seus membros segundo a cor ("pretos" e "pardos") e também segundo as naçôes africanas ("angola”, "mina” e outras). ${ }^{8}$ Esse breve histórico mostra como, ao longo do tempo, vão sendo criadas no interior das irmandades "identidades contrastivas", ou seja, que se definem em contraposição a outras previamente estabelecidas, ${ }^{9}$ que levam a um processo de segmentação/reagrupamento que faz surgirem novas devoções e novos rearranjos entre os grupos.

Esse longo processo de recomposição de grupos no interior das irmandades se apresenta como uma das mais ricas abordagens para a investigação sobre a inserção dos escravos nascidos na África na sociedade colonial. $\mathrm{O}$ artigo aqui apresentado mostra como essas duas esferas, a saber, a organização dos grupos étnicos/procedência e as devoções católicas se articu- 
lam no Brasil colonial para dar a essa geração de escravos nascidos na África um lugar próprio no universo da sociedade colonial: por um lado continuam sendo vistos como minas, angolas e moçambiques, mas por outro, uma vez convertidos, escapam ao estigma da gentilidade e conseguem ser reconhecidos como súditos da coroa, a quem prestam obediência, aprendendo a viver e a tirar proveito das regras da sociedade colonial.

\section{As irmandades de homens pretos na cidade do Rio de Janeiro}

Na cidade do Rio de Janeiro, a Matriz de São Sebastião inaugurada em 1583 é uma das poucas igrejas da cidade a permitir a presença de irmandades de pretos e pardos. Ao longo do século XVII aí se organizam quatro devoções: NS do Rosário, São Benedito, São Domingos e NS da Conceição. As primeiras são de "Homens Pretos" e a última de "Homens Pardos”. Em 1667 as devoções do Rosário e São Benedito se unem, formando uma única irmandade. As outras duas se instituem em irmandade em data ignorada, ainda no século XVII. ${ }^{10}$ Alvo de constantes reclamações em decorrência do modo como praticam suas devoções, no ano de 1700, os irmãos do Rosário e São Domingos dão início à construção de capelas próprias. A Igreja do Rosário só é inaugurada em 1725; a de São Domingos, menor e mais pobre, fica pronta já em 1706. Ao longo do século XVIII essas e outras irmandades de homens pretos se espalham pela cidade, mostrando o esforço dos africanos em se agrupar, tomando como base as chamadas naçôes. ${ }^{11} \mathrm{Na}$ cidade do Rio de Janeiro existem devoções organizadas por africanos vindos de Angola e do Congo, como a irmandade do Rosário; outras onde predominam o chamado Gentio de Guiné, como a da Lampadosa; e por fim as devoções dos africanos vindos da Costa da Mina, como Santo Antônio da Mouraria (1719), Santo Elesbão e Santa Efigênia (1740). ${ }^{12}$

A primeira metade do século XVIII é o período de entrada do maior contingente de escravos vindos da África Ocidental — os chamados minas - para o Rio de Janeiro. Eles recebem esse nome por procederem da Costa da Mina, designação topográfica surgida no século XV. A partir de 1690, quando se intensifica o tráfico na região, a surge a denominação Costa dos 
Escravos que coincide, aproximadamente, com a área dos povos de língua gbe. ${ }^{13}$ No Brasil os povos de língua gbe incluem tanto os minas do Rio de Janeiro, no século XVIII, quanto os jejes da Bahia, no século XIX. ${ }^{14}$ Os primeiros registros regulares de embarcações chegadas da Costa dos Escravos e adjacências localizados por mim datam de 1693. No período de 1693 a 1695 chegam à Bahia pelo menos 22 embarcações, a maioria patachos e sumacas, sendo que quatorze delas vêm da Mina, cinco de São Tomé e três da Mina com escala em São Tomé. ${ }^{15} \mathrm{Na}$ correspondência dos governadores, as embarcações destinadas à Costa da Mina são mencionadas pela primeira vez em 1703, quando d. Rodrigo Costa, governador da Bahia (17021705), escreve ao rei de Portugal informando que começara "há poucos anos" a remessa de embarcaçôes da cidade do Rio de Janeiro para resgatar escravos na Costa da Mina. ${ }^{16}$ Assim sendo, tanto a Bahia quanto o Rio de Janeiro incrementam um comércio regular de escravos com a Costa da Mina na virada do século XVII para o XVIII. Não por acaso tem início justamente nesses anos a exploração do ouro nas Minas que passa a ser usado pelos negociantes do Brasil para comprar escravos na África. ${ }^{17}$

A irmandade do Rosário da cidade do Rio de Janeiro é dirigida por africanos de Angola. Em seu compromisso de 1759 a Irmandade passa a admitir, em sua mesa, africanos de todas as procedências. ${ }^{18}$ Ao longo de toda a primeira metade do século, privados das esferas de poder na Irmandade do Rosário, os minas passam a organizar suas próprias devoções. Já na década de 1740 quatro delas merecem destaque. Na capela de São Domingos estão alocadas a devoção do Menino Jesus e a devoção conjunta de Santo Elesbão e Santa Efigênia. Na Igreja do Rosário são instaladas as devoções de Santo Antônio da Mouraria e NS da Lampadosa. ${ }^{19}$

A partir dos anos de 1750 essas pequenas devoções concentradas nas Igrejas do Rosário e São Domingos iniciam a construção de capelas próprias. Algumas delas não deixam registros. Outras resistem à política de estrangulamento do marquês de Lavradio e se consolidam construindo igrejas próprias como é o caso de Santa Efigênia, Lampadosa e Senhor Jesus do Cálice. ${ }^{20}$ Apesar das constantes proibições, as folias continuam saindo às ruas até 1808 quando ficam proibidas por parecerem uma afronta à recém chegada Corte portuguesa. ${ }^{21}$ 


\section{A Irmandade de Santo Elesbão e Santa Efigênia ${ }^{22}$}

A Irmandade de Santo Elesbão e Santa Efigênia é constituída basicamente por africanos de língua gbe, vindos da Costa dos Escravos. No ano de 1740 esses santos já são venerados por um grupo de aproximadamente trinta pessoas numa casa particular na Freguesia da Candelária quando seus devotos decidem transferir as imagens para a capela de São Domingos, localizada na mesma freguesia. Existe nessa igreja outra devoção de pretos minas onde estão reunidos povos de outras áreas que não a Costa dos Escravos. ${ }^{23}$ Por motivos desconhecidos, os dois grupos ditos minas se reúnem no interior da mesma capela mas permanecem separados em suas devoçóes. Por outro lado os devotos de Santo Elesbão partilham sua irmandade com africanos procedentes de Moçambique, Cabo Verde e São Tomé, também sem qualquer proximidade lingüística ou cultural em relação aos povos de língua gbe. ${ }^{24}$

Encobertos por essas grandes categorias de procedência (Mina, Moçambique, Cabo Verde e São Tomé) existem diversos pequenos grupos étnicos invisíveis aos olhos do pesquisador e mesmo de muitos de seus contemporâneos. Tanto categorias mais abrangentes como os grupos de procedência quanto categorias mais restritas como os grupos étnicos são acionados no interior das irmandades, sendo imprescindível entender qual deles está atuando em cada situação. Na Igreja de Santo Elesbão e Santa Efigênia as fronteiras entre os grupos estão bem demarcadas. Internamente reconhecem os diferentes grupos, procurando dar a cada um o devido lugar. Em relação aos demais demarcam com clareza mecanismos de controle e exclusão. De acordo com o compromisso de 1740 o ingresso na Irmandade é feito da seguinte forma.

"Antes que o Juiz e mais oficiais da mesa desta Santa Irmandade queiram admitir e fazer assento à qualquer pessoa que o queira ser sendo preto ou preta, primeiro examinarão com exata diligência a terra e nação donde vieram. Achando serem naturais e que são oriundos da Costa da Mina, Cabo Verde, Ilha de S. Thomé ou de Moçambique logo se fará assento nela, dando de sua entrada quatro patacas. E da mesma nação é que se hão de eleger o Juiz, escrivão, Procurador e Juiza e Irmãos e Irmãs de Mesa que sempre hão de servir na Santa Irmandade, exceto o Tesoureiro que, como já se disse em seu lugar, seja homem branco os quais e mulheres e pardos e pardas que- 
rendo por sua devoção serão admitidos por irmãos desta Santa Irmandade. E de nenhuma sorte se admitirão pretas de Angola, nem crioulas, nem cabras ou mestiças." 25

A análise da documentação da Irmandade mostra também como, ao longo dos anos, através de sucessivas alteraçôes, o compromisso explicita um conjunto de mecanismos que regulamentam a presença dos pequenos grupos. O principal grupo de procedência da irmandade é o grupo mina, composto pela reunião de pequenos grupos étnicos de língua gbe, vindos da Costa dos Escravos. ${ }^{26}$ Por ocasião da criação da Irmandade, em 1740, os chamados "irmãos fundadores" 27 já estão de alguma forma organizados de acordo com suas nações. Um exemplo dessas organizações é a Congregação dos Pretos Minas, surgida em data desconhecida. Em 1748 ela é governada por Pedro da Costa, substituído em data ignorada por Clemente Proença. Como as demais procedências (Cabo Verde, Moçambique, São Tomé) são francamente minoritárias na cidade, não parece haver dúvida sobre o fato de que os minas controlam a irmandade.

Nos primeiros quinze anos de existência a irmandade de Santo Elesbão fica alojada na Igreja de São Domingos. Em 1745 ela ganha um terreno no próprio Campo de São Domingos para a construção de sua igreja. ${ }^{28} \mathrm{~A}$ obra não demora a começar e já em 1747 é benta e assentada a pedra fundamental. Escritos em 1740, os vinte capítulos iniciais do Compromisso indicam uma agremiação ainda pouco regulamentada. Nos anos seguintes aumenta o número de devotos, sendo necessário dotar o compromisso de regras mais claras e rigorosas. A construção da igreja deve ter acirrado as divergências entre os diferentes grupos no interior da Irmandade acarretando na primeira reforma do compromisso, no ano de 1748. A igreja é construída em apenas sete anos, sendo inaugurada com um culto público em 28 de agosto de 1754. Novas alteraçôes do compromisso mostram intensos conflitos pelo controle dos recursos da igreja e também as estratégias engendradas para isso.

A presteza com que a obra é levada a cabo faz pensar na origem dos recursos utilizados pelos irmãos para realizá-la, em tão curto prazo. Além de escravos e forros pobres, a irmandade certamente conta com irmãos mais afortunados. Alguns indícios levam a crer que a direção da irmandade reúne certo patrimônio, acumulado por seus próprios membros através de seu 
trabalho e quem sabe de suas ligações com o tráfico de escravos. Inicialmente não deve ser desprezado o fato de o florescimento da irmandade ser paralelo à consolidação do reino do Daomé (1734-1750). Mas a ligação da devoção a Santo Elesbão com o mar é mais explícita. Santo Elesbão é protetor dos navegantes e sua devoção no Rio de Janeiro surge numa casa particular ainda não identificada na Candelária, a freguesia portuária da cidade. ${ }^{29}$ Além disso a própria documentação da irmandade faz menção ao mar. Uma ata da igreja transcreve um roteiro de viagem pelos portos da Costa da Mina que é fornecido por um piloto anônimo que conhece em detalhes todo o litoral da Costa dos Escravos. Por fim, pelo menos um irmão registra em seu testamento que pratica pequenos negócios com escravos.

A leitura dos testamentos dos irmãos falecidos mostra que esmolas, missas, anuais atrasados e outros legados deixados para a irmandade transferem uma parte importante do patrimônio individual dos irmãos para a coletividade. Embora os recursos arrecadados não sejam suficientes para constituir um sólido patrimônio (como acontece em irmandades mais ricas), pelo menos garantem uma circulação e redistribuição de recursos que, uma vez depositados na irmandade, passam contribuir para o sustento do culto e do grupo de congregados. É curioso notar que embora o compromisso assegure o sustento da família do irmão falecido esta não deve ser das maiores despesas. Pelos testamentos é possível verificar que muitos dos irmãos não têm filhos (ou não declaram tê-los), o que facilita a transferência dos recursos para o interior da irmandade. Marina Martins, uma devota de NS dos Remédios - devoção criada pelos mina-mahis na Igreja de Santa Efigênia em 1786 - declara em seu testamento que possui uma escrava que deve ser vendida para pagar seus legados. Pede que seu corpo seja conduzido à capela de Santo Elesbão por seis padres com velas de meia libra e sepultado com o hábito de São Francisco. Deixa para NS dos Remédios 6,400 réis, mais 4,000 para outra irmandade, mais esmola para missas. Declara ter uma filha parda, nascida antes de seu casamento, em relação a quem determina:

"não lhe deixo nada, porque não tenho, mas feitas, e pagas as minhas disposições se ficar algum trapinho meu testamenteiro, preferirá a ela primeiro, que outra qualquer pobre." ${ }^{30}$ 
O Império de Santo Elesbão na cidade do Rio de Janeiro • 67

Esse exemplo mostra que o pagamento do enterro, a celebração das missas e as esmolas deixadas para as irmandades são compromissos anteriores à constituição de um patrimônio familiar a ser deixado para a descendência. Quanto aos bens arrolados nos testamentos são poucos. Uns possuem casa, sempre dita "pobre". Quase todos os que adquirem alguma posição têm um ou dois escravos, sempre africanos, de diversas nações. A maioria tem apenas "uns trastes" e algum dinheiro. Muitos não têm nada, deixando em seu testamento apenas suas últimas vontades... um enterro digno, missas e velas. As mulheres costumam ter jóias de ouro. Assim imbuídos da justeza de seus atos ou forçados pelas circunstâncias - a maioria dos irmãos deixa, de um modo ou de outro, praticamente todos seus bens para a Irmandade ou para membros dessa agremiação, usualmente seus testamenteiros.

\section{Um rei mahi na corte de Santo Elesbão}

Em 1740 quando é oficialmente instituída a irmandade, criada por trinta irmãos, já reúne aproximadamente setenta pessoas. Nos anos seguintes a irmandade cresce em número de membros e em patrimônio. $\mathrm{O}$ crescimento da irmandade faz com que os diferentes grupos - organizados em torno de congregaçóes, reinados ou devoções - comecem a se desentender e a disputar em nome de "preferências e maiorias". ${ }^{31}$ Esses conflitos no interior do grupo parecem ser constitutivos do relacionamento entre eles. Em data desconhecida entre 1748 e 1762 surgem graves desentendimentos no interior da Congregação dos Pretos Minas, a maior agremiação existente no interior da irmandade. Por ocasião da sucessão de Clemente Proença, duas facções se apresentam no interior dessa Congregação. O conflito entre elas acaba gerando um cisma que leva à criação de pelo menos uma nova congregação liderada pelos mahis. ${ }^{32}$ Como resultado dessa dissidência, no ano de 1762, toma posse como rei da nova Congregação formada pelos Mahis, o capitão Ignácio Gonçalves do Monte.

A tradição da escolha de reis e rainhas vem de Lisboa. A Mesa da Irmandade de NS do Rosário do Mosteiro de São Domingos instituída em 1567 é composta por cargos executivos (juiz, procurador, etc.) e mais uma corte com rei, duque, conde e outros nobres, representando a sociedade 
estamental portuguesa no interior da irmandade. Assim sendo, a associação dos reinados das folias aos soberanos africanos deve ser buscada não numa referência imediata ao passado individual dos grupos, mas ao modo como já em Portugal esses reinos pagãos foram legitimados no interior do universo cristão. A diferença entre a corte da irmandade do Rosário de Portugal e as cortes encontradas no Brasil é que aqui os dois segmentos da Mesa (os cargos executivos e os títulos de nobreza) aparecem separados: enquanto os juízes e os demais membros da Mesa encarregam-se da direção das irmandades, os reis encabeçam agremiações étnicas, denominadas "reinados", "estados imperiais" ou simplesmente "folias". Essas folias, assim como as devoções a que estão associadas, constituem verdadeiras linhagens religiosas que se espalham pela cidade. A folia da Lampadosa, inicialmente instalada na Igreja do Rosário - famosa pelas festas do rei congo - elege também reis e rainhas. Já as folias de Santana e de Santo Elesbão, ambas alojadas na Igreja de São Domingos, elegem imperadores e imperatrizes. A Irmandade de Santana funda o Império do Divino Espírito Santo e a Irmandade de Santo Elesbão e Santa Efigênia o Império de Santo Elesbão. ${ }^{33}$

Assim sendo, por ocasião criação do Estado Imperial em 1764, os minas já estão divididos em pelo menos duas facçôes, cada uma governada por um rei mahi, Ignácio Gonçalves do Monte que governa além de seus nacionais também os agolins, savalus e [iannos]; e um rei, provavelmente dagomé, que representa o grupo mais importante e provavelmente fundador da irmandade que permanece na Congregação dos Pretos Minas.

Os dagomés da cidade do Rio de Janeiro devem ter sido traficados a partir do final do século XVII e ao longo de todo o século XVIII como resultado dos incessantes conflitos que se estendem por toda a Costa dos Escravos nesse período, gerando prisioneiros e futuros escravos de todas as partes envolvidas nos conflitos. ${ }^{34}$ Vinte anos depois de aqui chegados alguns deles já estariam alforriados e com algum patrimônio, de modo a liderar a institucionalização da devoção a Santo Elesbão e Santa Efigênia no ano de 1740. Os mahis traficados para o Brasil provavelmente são prisioneiros de guerra vendidos pelos daomeanos. Os conflitos entre o Daomé e os mahis se acentuam a partir do início da década de 1730 e se estendem por todo o século. ${ }^{35}$ Isso indica que provavelmente teriam sido traficados 
em Ajudá pelos próprios daomeanos, em troca de ouro, daí sua presença em Salvador, mas também no Rio de Janeiro e Minas Gerais.

Para oferecer a esses pequenos grupos alguma esfera de participação, poder e principalmente prestígio mas, ao mesmo tempo, submetê-los a uma autoridade maior, a Mesa da irmandade resolve criar um Estado Imperial. O Estado Imperial de Santo Elesbão é governado por um Imperador e sua corte, composta por até sete reis e outros cargos de nobreza. Cada rei é responsável por seus "nacionais" também chamados "parentes" ${ }^{36}$ A criação de uma nova hierarquia paralela à mesa diretora da irmandade (a chamada folia ou estado imperial) consagra a partir de 1764, na esfera da organização religiosa formal, uma segmentação já existente ao nível da organização dos grupos. Através das folias e sob o amparo da Irmandade, os grupos étnicos afloram no interior da igreja. ${ }^{37}$ Durante o reinado do capitão Ignácio (1762-1783) acontecem conflitos no interior da Congregação Mahi que é abandonada pelos agolins e os savalus, que passam a eleger seus próprios reis. Provavelmente também esses reinados organizaram as suas folias, vindo a constituir, a partir de 1764, a corte do Imperador de Santo Elesbão. A criação do Império se apresenta como uma solução: por um lado a figura do imperador cria um elo entre os reis e por outro se sobrepõe a eles, restituindo a ordem e a hierarquia no seio da Irmandade. ${ }^{38}$

De acordo com o compromisso de 1764 apenas irmãos com patrimônio podem ser eleitos reis das folias, devendo, à sua custa, sustentar o reinado e sua corte. ${ }^{39} \mathrm{O}$ corpo documental mais sólido sobre a presença dos mahis no interior da irmandade data da década de 1780. Trata-se de uma ata da Congregação Mahi que indica a existência de 200 filiados. De acordo com levantamento feito para o vice-rei Luiz de Vasconcellos, na década de 1780 , a população escrava da cidade gira em torno de 9.700 homens e 7.100 mulheres. ${ }^{40}$ Se considerada uma população escrava de 20.000 e tomados os mahis da Congregação como total dos mahis da cidade, e todos como escravos, eles corresponderiam, grosso modo, a 1\% da população escrava da cidade. Embora seja uma vaga estimativa, esses números dão alguma medida da importância desse grupo na vida da cidade.

Por ocasião da sua morte, em 1783, o capitão Ignácio Gonçalves do Monte é sepultado na Igreja de Santo Elesbão e Santa Efigênia. Em seu 
testamento declara pertencer a essa irmandade. Sua sucessão abre uma disputa que fica registrada na referida ata da Congregação Mahi, curiosamente não mencionada por ele em seu testamento. O sucessor do capitão Ignácio na Congregação Mahi é Francisco Alves de Souza, regente da Congregação durante o reinado do capitão Ignácio. Francisco chega ao Rio de Janeiro em 1748, depois de ter passado algum tempo na Bahia. É através de seu relato que a história do grupo se perpetua. ${ }^{41}$

Em 1748, que cheguei a esta capital vindo da cidade da Bahia, achei já esta congregação ou corporação de pretos minas de várias naçôes daquela Costa, a saber Dagomé, Maqui, Ianno, Agolin, Sabaru todos de língua geral com muita união tendo por rei de tal congregacão a um Pedro da Costa mimoxo também da mesma nação e depois faleceu este, nomearam para existir no mesmo cargo a Clemente de Proença com o mesmo título a que exerceu há muitos anos e continuando a tempo começaram os pretos a zingarem as naçōes umas com as outras, buscando preferências de maiorias. Ao que deu ocasiāo ao que as naçôes Maki, Agolin, Ianno, Sabaru saírem do jugo Dagomé escandalizados e afrontados de alguns ditos picantes que os dagomé lhes diziam, procuraram fazer o seu rei e com efeito o fizeram na pessoa do Capitão Inácio Gonçalves do Monte no ano de 1762 por ser verdadeiro makino e este foi o primeiro que fez termo e endireitou e aumentou esta congregação. ${ }^{42}$

A cronologia da Congregação Mahi permite perceber que os grupos étnicos estão organizados na cidade provavelmente antes da fundação da irmandade, no ano de $1740 .{ }^{43}$ Não deve ser outra a razão para, por ocasião do surgimento dessa agremiação, a filiação a ela atender justamente a esse critério. Conforme a narrativa de Francisco em 1762 algumas nações conseguem escapar ao "jugo" dos dagomés e constituir uma nova Congregação cujo rei passa a ser o capitão Ignácio que é mantido como rei até a data de sua morte em 1783. O capitão Ignácio, considerado "um verdadeiro maquino", lidera um conjunto de pequenos grupos étnicos minas (entre eles os mahis, agolins, savalus e ianos), todos eles adversários dos dagomés. Isso indica que, entre os oponentes dos dagomés, seriam os mahis o grupo de maior projeção. ${ }^{44}$ À diferença da mesa da irmandade onde as relações entre os irmãos estão mais institucionalizadas, no interior da folias o poder é exercido de forma mais personalizada. A morte do capitão Ignácio abre 
nova crise não apenas no interior da Congregação, mas no conjunto da irmandade, fazendo com que os minas voltem a "zingar" entre si.

Segundo o atestado de óbito, Ignácio Gonçalves do Monte morre em 27.12.1783. ${ }^{45}$ É amortalhado no hábito de São Francisco, acompanhado pelo pároco com dez sacerdotes e sepultado na Capela de Santa Efigênia. ${ }^{46}$ Por declarar não saber escrever, Ignácio dita seu testamento, supostamente na presença dos irmãos da irmandade. ${ }^{47}$ Deixa viúva Victoria Correa da Conceição com quem declara não ter filhos. Acrescenta ainda não tê-los tido com qualquer outra mulher, a qualquer tempo. Nomeia como testamenteiros a viúva, Francisco do Coito Suzano e José dos Santos Martins. Informa ter comprado sua alforria por 350,000 réis. Diz ser "barbeiro e sangrador", atividade que desenvolvida numa oficina localizada junto a uma venda de secos e molhados, ao lado de sua casa. O testamento não faz menção a bens de raiz. Deixa livre um escravo e recomenda expressamente que sejam colocados em dia os anais da irmandade para a qual deixa uma esmola de 10,400 réis. Dá detalhes sobre o enterro e as missas de corpo presente, demonstrando estar disposto a gastar bastante com seu funeral. Todas essas iniciativas ficam a cargo de seus testamenteiros a quem recomenda que cuidem também do dinheiro de seus "patrícios" explicando que eles "me dão a guardar seu dinheiro por mais seguros em minha mão os vêem". Pede também que atentem para receber "algum dinheiro que empresto a várias pessoas". Adverte sobre a existência de "um livrinho que tenho na minha gaveta aonde trago as mais cousas e valores", onde toda sua movimentação financeira está anotada. Declara ainda que é testamenteiro da defunta Quitéria Fernandes da Silva preta forra de cujo testamento ainda não teria dado conta, "por se não ter acabado o tempo estipulado nele para a sua conta". ${ }^{48}$

Os testamenteiros têm total autonomia para negociar o patrimônio com vistas ao cumprimento dos legados. Além de primeira testamenteira a viúva é também a única herdeira do saldo dos legados. O testamento nomeia três personagens certamente fundamentais nos conflitos que envolvem a sucessão de Ignácio Monte. A primeira é a viúva Vitória Correa da Conceição, que ele explica ser sua "parenta por sangüinidade", "por ser ela filha do meu avô [...] bem conhecido Rei que foi entre os gentios daquela 
Costa no Reino de May ou Maquis". ${ }^{49}$ Os outros dois, supostamente membros da Congregação, não estão entre os fundadores da devoção das almas ou da devoção de NS dos Remédios, ambas compostas pelos partidários do regente Francisco Alves de Souza, sucessor do capitão Ignácio no governo da Congregação, contra quem a viúva abre uma longa demanda.

$\mathrm{Na}$ ata da Congregação, documento que relata a morte de Ignácio, consta que estão presentes na ocasião alguns membros da Congregação cujos nomes são arrolados no texto. Nenhum deles é indicado como testamenteiro ou recebe qualquer outra menção no testamento, cabendo, portanto, a dois ausentes essa tão importante função: Francisco do Coito Suzano e José dos Santos Martins $s^{50}$ estão certamente entre os "parciais da viúva” em seu plano de tornar-se a "imperatriz de toda a Costa da Mina", como acusam seus inimigos, os partidários do regente. ${ }^{51}$ A leitura combinada da ata da irmandade e do testamento permite perceber o conflito aberto no interior da Congregação Mahi por ocasião da sucessão. De um lado está Francisco, regente da Congregação durante o reinado de Ignácio; de outro a viúva. De acordo com o testamento em nenhum momento Ignácio desautoriza sua mulher a quem deixa a responsabilidade de guardar seus pertences. Por outro lado, ao arrolar seus bens não faz qualquer menção ao cofre e mais "trastes" da Congregação que, segundo a ata, estariam em seu poder e que, por ocasião de sua morte, a viúva se recusa a devolver aos irmãos, decorrendo daí toda a disputa entre ela e os parciais de Francisco.

A documentação não apresenta os possíveis interesses ou preferências de Ignácio. As confusões armadas pela viúva — que certamente para maior desgosto do regente se chama Vitória — fazem lembrar os acontecimentos que marcam a vida no reino do Daomé por ocasião da morte de um rei. No Daomé, o reino é um legado do morto para seus descendentes, mas há que disputá-lo. $\mathrm{Na}$ irmandade os reis são eleitos. Ignácio não tem filhos, mas mesmo que os tivesse, possivelmente seriam crioulos, portanto impossibilitados de suceder o pai. A sucessão deixa de ser herança familiar para recair sobre outro tipo de parentesco, o parentesco étnico, onde todo homem mahi é parente de outro mahi, sendo essa, no interior da igreja a condição para a elegibilidade. Dessa forma, a sucessão de um rei já tradicionalmente tumultuada gera na irmandade certamente conflitos ainda maiores. 
Por outro lado, à diferença do que ocorre nas disputas sucessórias tradicionais, existem na irmandade instâncias superiores às quais as partes em litígio podem apelar tanto para dirimir dúvidas, quanto para manipular esferas de poder. Por ocasião da sucessão de Ignácio os parciais da viúva recorrem ao Tribunal da Relação do Rio de Janeiro e ao Vice-rei. Já os parciais do regente se apelam a d. Maria, rainha de Portugal. ${ }^{52}$ Agem na condição súditos da Coroa portuguesa.

\section{Os mahis e o tráfico na Costa dos Escravos}

A organização das agremiações religiosas de pretos minas da cidade do Rio de Janeiro no século XVIII é contemporânea de uma série de acontecimentos relacionados ao tráfico atlântico e aos conflitos a ele associados na própria África Ocidental. Mesmo correndo o risco de uma simplificação perigosa gostaria de mencionar aqui alguns acontecimentos relativos ao tráfico na Costa dos Escravos no século XVIII. Os conflitos entre o reino do Daomé e os mahis se estendem ao longo de todo o século XVIII, mas se agravam depois de 1748 quando, feita a paz com Oió, o Daomé se volta contra seus inimigos menores, entre eles os mahis. Esses conflitos convivem com diferentes interesses que geram também algumas formas de aliança. ${ }^{53}$ Por outro lado, os conflitos que envolvem Daomé, Oió e povos da hinterlândia apontam para um outro conjunto de acontecimentos menos estudados. Durante praticamente todo o século XVIII os mahis estão sob influência de Oió e não do Daomé. Na segunda metade do século XVIII quando os conflitos pelo controle das rotas do tráfico atlântico se acirram assim como os reinos do Daomé e Oió os mahis também já são reconhecidos como comerciantes de escravos na hinterlândia, de onde comerciam inclusive com os daomeanos que controlam o acesso das rotas da hinterlândia ao porto de Ajudá, deixando a seus concorrentes outros portos menores, como é o caso de Porto Novo. ${ }^{54}$

Essa perspectiva é fundamental para retomar à análise da presença mahi no interior da irmandade de Santo Elesbão e Santa Efigênia. Os dagomés presentes na igreja devem ter chegado à cidade entre 1720 e 1740, em decorrência das guerras de consolidação do reino do Daomé. Os mahis devem ter começado a ser traficados na década de 1730 e podem ter chegado 
em vários períodos, especialmente após a guerra de 1731 e também após o sítio da cidade de Gbowele em 1753. Entretanto, na década de 1780, quando ambos se enfrentam por ocasião da morte do capitão Ignácio, já são passados, em alguns casos, mais de cinqüenta anos. Em 1780, os minas da cidade formam uma bem organizada e razoavelmente rica comunidade, distribuída por várias devoçôes e irmandades, com patrimônio superior a qualquer outro grupo de africanos da cidade. ${ }^{55}$ Certamente esses devotos já não se vêem como míseros traficados arrastados seminus pelas ruas da cidade. Ao contrário, tentam esconder esse tempo de suas vidas, mencionando na história da irmandade apenas o passado guerreiro e glorioso deixado em suas terras. Nos anos de 1780, tanto dagomés quanto mahis se vêem como membros desterrados de importantes reinos africanos. ${ }^{56}$

Por fim é importante destacar que os anos de escravidão, a alforria, a vida cristã e a salvação eterna na qual investem quase todos os seus bens não afastam esses devotos do profundo sentimento de que são dagomés, mahis e savalus. O capitão Ignácio Gonçalves do Monte, rei dos mahis na cidade do Rio de Janeiro, neto de um rei mahi em sua terra, morre sem deixar descendentes. Assim como ele, a maioria dos demais devotos da Irmandade declara em seus testamentos não ter filhos. De acordo com o sistema de identificação dos escravos adotado no Brasil no século XVIII, é "crioulo" todo filho de um escravo africano nascido no Brasil. O crioulo é o escravo ou escrava, filho de mãe gentia que nasce no âmbito da sociedade colonial. Magdalena Costa, uma "preta forra crioula", é filha natural de Josepha da Costa, uma "preta mina" e mãe do pequeno Custódio, "escravo", batizado em 1745. ${ }^{57}$ Esta curta genealogia permite perceber que ser crioulo é, nessa época, uma condição provisória sucedida, na geração seguinte, pela inserção numa identidade genérica de "escravo" que iguala a todos na esfera mais baixa da sociedade estamental. A inserção dos filhos dos africanos na sociedade colonial como crioulos impede a constituição de uma descendência étnica no âmbito da sociedade escravista. ${ }^{58}$ Não existem mahis ou dagomés nascidos no Brasil que possam, pelas regras de descendência aqui vigentes, dar perenidade ao grupo.

Nessas condições, a sobrevivência de um grupo étnico no cativeiro está ligada ao próprio tráfico à constante chegada de novos integrantes. Tal 
perspectiva explica o pouco caso com os crioulos e o especial cuidado com os mortos. Ser mahi longe do reino mahi é construir uma identidade voltada para o passado com base numa rede étnica geracional. Isso é possível na medida em que, no século XVIII, as mais diversas esferas da sociedade colonial envolvidas no tráfico sequer vislumbram o fim desse infame comércio. É sustentado pelo pensamento da perenidade do tráfico que dagomés e mahis se enfrentam e disputam interesses no interior da irmandade, mostrando quanto, na segunda metade do século XVIII, ainda estão arraigadas nessa sociedade os pressupostos da legitimidade do tráfico já tão discutido na Europa, especialmente na Inglaterra.

Os mahis, assim como outros africanos, não se "criolizam", ou são "crioulizados", por forças das circunstâncias históricas resultantes do tráfico. ${ }^{59}$ Eles presenciam e reagem a essa situação de diferentes formas. Na irmandade de Santo Elesbão e Santa Efigênia, mantendo algumas de suas tradições e abrindo mão de outras, os irmãos buscam uma saída pensando em si mesmos e não em sua descendência. Esse sentimento do presente está certamente associado ao fato de a maioria deles não ter filhos, ou não considerá-los como importantes no processo de identificação étnica. A Congregação Mahi é uma comunidade voltada para os "irmãos" e "nacionais" numa fraternidade geracional que atravessa o oceano, ligando o reino mahi do Império de Santo Elesbão ao reinventado "potentado reino mahi da Costa da Mina”. De acordo com as palavras do secretário da Congregação Mahi:

"a maior paixão que tenho é de não ver os nossos nacionais todos católicos fazendo serviços a Deus que é o fim para o que fomos nascidos." ${ }^{0}$

\section{Notas}

${ }^{1}$ Um conjunto de novos trabalhos sobre tráfico atlântico e história da África tem contribuído para esse debate. Destaco aqui os trabalhos de Paul E. Lovejoy. Transformations in slavery: a history of slavery in Africa. Cambridge University Press. 1983; Joseph Miller. Way of death: merchant capitalism and the Angolan slave trade 1730-1830. Princeton University Press. 1988; Patrick Manning. Slavery and African life. Occidental, Oriental, and African slave trades. Cambridge University Press. 1990; John K. Thornton. Africa and Africans in the making of the Atlantic world, 1400-1680. Cambridge University Press. 
1992; David Eltis. The rise of African slavery in the Americas. Cambridge University Press. 2000.

${ }^{2}$ A especificidade da situação dos escravos nascidos na África no universo da escravidão das Américas começa a merecer a atenção dos historiadores, mas enfrenta ainda o problema do reconhecimento das fontes adequadas para a análise e da freqüente dispersão desse material. Em trabalhos relativos ao Brasil, poucos autores têm enfocado a presença de africanos vindos da África Ocidental para o Rio de Janeiro. Para o século XIX ver Mary Karasch. A vida dos escravos no Rio de Janeiro. 1808-1850. São Paulo. Companhia das Letras. 2000 (edição original em inglês de 1987) e Carlos Eugênio Líbano Soares. A capoeira escrava e outras tradiçôes rebeldes no Rio de Janeiro (1808-1850). São Paulo. Unicamp/ CECULT. 2001. Para o século XVIII ver Mariza de Carvalho Soares. Devotos da cor. Identidade étnica, religiosidade e escravidão no Rio de Janeiro, século XVIII. Rio de Janeiro:Civilização Brasileira. 2000.

${ }^{3}$ Sobre grupos de procedência ver Mariza de Carvalho Soares. Devotos da cor... Ver também Fredrik Barth. "Grupos étnicos e suas fronteiras". In O guru, o iniciador e outras variaçôes antropológicas. Organização de Tomke Lask. Rio de Janeiro. Contra Capa. 2000; e Paul Lovejoy. "Enslaved africans in the diaspora". In: Paul Lovejoy (edited by) Identity in the shadow of slavery. London/New York. Continuum. 2000.

${ }^{4}$ Destaco trabalhos como os de Stuart Schwartz. Segredos internos. Engenhos e escravos na sociedade colonial (primeira edição em inglês, 1985). São Paulo. Companhia das Letras. 1995; João José Reis. Rebelião escrava no Brasil. A história do levante dos malês (1835). São Paulo: Brasiliense. 1986; Silvia Hunold Lara. Campos da violência. Escravos e senhores na capitania do Rio de Janeiro. 1750-1808. Rio de Janeiro: Paz e Terra. 1988.

5 "Preto" é um termo de uso generalizado no século XVIII. As irmandades são oficialmente denominadas "Homens Pretos" e "Homens Pardos".

${ }^{6} \mathrm{O}$ compromisso de 1618 de Santa Casa da Misericórdia de Salvador estabelece sete condições para filiação, entre elas ser "limpo de sangue", condição ligada ao Estatuto da Pureza de Sangue. No Rio de Janeiro a Santa Casa de Misericórdia é a primeira agremiação leiga a instituir esse critério de exclusão. A J R. Russell-Wood. Fidalgos e filantropos. A Santa Casa de Misericórdia da Bahia, 1550-1755. Brasília: EdUnB. 1981; Ver também Bernard Vincent. "Lês confréries de noirs dans la Péninsule Ibérique (XVe-XVIIIe siècles). In David González Cruz (editor) Religiosidad y costumbres populares em Iberoamérica. Actas Del Primer Encuentro Internacional celebrado em Almonte-El Rocio (España) del 19 al 21 de febrero de 1999; e John Thornton. Africa and Africans..., pp.183-205.

${ }^{7}$ Compromisso da Irmandade de NS do Rosário dos Homens Pretos do Convento de São Domingos de Lisboa, capítulo 7. Patrícia Ann Mulvey The black lay brotherhoods of colonial Brazil: a history. City University of New York, Ph.D. 1976. Xerox University Microfilms. Ann Arbor. Michegan 48 108. "Appendix B”. pp. 255-263.

${ }^{8}$ Nas irmandades do Rosário, muitas delas criadas ainda no século XVII, são aceitos pretos de um modo geral, mas apenas os angolas e congos e algumas vezes crioulos têm acesso a cargos na irmandade. No século XVII a Irmandade de NS do Rosário de Salvador 
aceita apenas angolas e crioulos. A Irmandade de Santo Antônio do Categeró aceita qualquer pessoa, mas restringe o acesso aos cargos a angolas e crioulos. No Rio de Janeiro apenas após 1759 a Irmandade do Rosário abre aos africanos vindos da Costa da Mina a possibilidade de integrar a Mesa diretora. Sobre a Irmandade de Santo Antônio do Categeró, ver A. J. R. Russell-Wood. Fidalgos e filantropos..., p. 108. Na segunda metade do século XVIII, por exigência régia (ainda não muito bem esclarecida na documentação consultada) os compromissos retiram esse tipo de restrição. Compromisso da Irmandade de NS do Rozario e Sam Benedito do Rio de Janeiro retira a restrição em 1759. AHU cód. 1950, capítulo 12, parágrafo 33. Agradeço a cópia desse documento a Larissa Viana. O compromisso da Irmandade de Santo Elesbão e Santa Efigênia faz o mesmo em 1767 onde no capítulo 25 reformula o capítulo 10 que impede a entrada de angolas. Arquivo da Irmandade de Santo Elesbão e Santa Efigênia, sem código.

${ }^{9}$ Faço aqui referência à noção de identidade contrastiva proposta pelo antropólogo Roberto Cardoso de Oliveira. Identidade, etnia e estrutura social. São Paulo. Pioneira. 1976.

${ }^{10}$ Olympio de Castro. "Memórias sobre a Irmandade de NS do Rosário e São Benedito dos Homens Pretos do Rio de Janeiro, escrita pelo Rev.mo Capelão Cônego Dr. Olympio de Castro (publicada na edição especial do Jornal do Commercio, comemorativa do Ano Santo) 1928." In Compromisso da Irmandade de NS do Rosário e S. Benedito dos Homens Pretos ereta na sua mesma igreja nesta Corte do Rio de Janeiro. 1928. pp. 47-58.

${ }^{11}$ Sobre a diversidade das nações africanas no Rio de Janeiro, ver Mariza de Carvalho Soares. “Descobrindo a Guiné no Brasil colonial”. RIHGB, ano 161, no 407, abr/jun 2000. pp. 71-94.

${ }^{12}$ Compromisso da Irmandade de Santo Elesbão e Santa Efigênia (1740). E Compromisso da Irmandade de Santo Antônio da Mouraria do Rio de Janeiro. Arquivo Nacional, Códice 825.

${ }^{13}$ Robin Law. The slave coast of West Africa 1550-1750. The impact of the Atlantic slave trade on an African society. Claredon Press. Oxford. 1991. pp. 14, 21-22. Ver mapa 18. No ano de 1741 começa a circular em Minas Gerais um vocabulário manuscrito da então chamada "Língua geral da Mina". Considerando que os povos da Costa dos Escravos começam a ser traficados para Minas Gerais por volta de 1700 e que já no ano de 1741 está sendo divulgado nessa capitania o referido vocabulário, é justo supor que ou esse intercâmbio lingüístico foi construído muito rapidamente no cativeiro ou já existia antes dele. Antônio da Costa Peixoto. Obra nova de Lingoa g. al de mina traduzida, ao nosso Igdioma por Antonio da Costa Peixoto, Naciognal do Rn..$^{\circ}$ de Portugal, da Provincia de Entre Douro e Minho, do comcelho de Filgr.as Que com curuzid. trabalho, e desvello, se expoz, em aprendella, p. ${ }^{a}$ tembem a emsignar, a q. ${ }^{m}$ for curiozo, e tiver von. ${ }^{\text {de }}$ de a saber E. ${ }^{\circ}$ Nas Minas Gerais, e Frg. ${ }^{a}$ de Barm. ${ }^{o u}$ Anno de 1741. Lisboa. Agência Geral das Colônias. 1949.

${ }^{14}$ Sobre os povos de língua gbe na Bahia ver Luis Nicolau Pares. "Transformations of the sea thunder voduns in the Gbe-speaking area and in the Bahian Jeje Candomblé." Enslaving Connections: Africa and Brazil during the Era of the Slave Trade. York University, Toronto. 11-15 October, 2000. vol 2. 
${ }^{15}$ Costa da Mina é a rubrica usada nos registros portugueses do tráfico atlântico onde não há menção à Costa dos Escravos.

16 “...os moradores do Rio de Janeiro, e das capitanias suas anexas, continuam a mandar, há poucos anos, várias embarcaçóes a resgatar escravos a Costa da Mina, o que até agora não faziam..." Arquivo Público do Estado da Bahia, 7, 108. Apud Pierre Verger. Fluxo e refluxo do tráfico de escravos entre o golfo do Benin e a Bahia de Todos os Santos dos séculos XVIII a XIX. 3ª edição. São Paulo: Corrupio. 1987. pp. 39-40.

${ }^{17}$ Ao iniciar o século XVIII já existem duas rotas de escravos em direção às lavras de ouro: a primeira sai da cidade de Salvador e, passando pela Vila de Cachoeira, segue por terra pelo Caminho do Sertão até as Minas; a outra sai de Salvador por mar, passa pelo Rio de Janeiro onde se junta à rota que vem da Mina para o Rio Janeiro, segue por mar para a Vila de Parati e daí sobe por terra a Serra da Mantiqueira até chegar às Minas. De acordo com o Livro de passaportes e guias da cidade de Salvador entre os anos de 1718 e 1729, saem dessa cidade 21. 238 escravos sendo que 19.500 deles com destino a Minas. Livro de passaportes e guias, 1718-1729. Arquivo Público Estado da Bahia, doc. 248.

18 "E como esta Irmandade forão seus fundadores homens pretos de todas as naçõez, não he justo deixem de ocupar todos os cargoz e empregos dela, pelo que ordenamoz que todas e qual quer pessoa que for Irmão desta Irmandade, possa servir e ocupar todos os cargoz dela, sem que para hisso se admita preferencia de melhoria desta, ou daquela nasção, tanto de Guinê, como da Costa da Mina," Compromisso da Irmandade de NS Rosário do Rio de Janeiro, 1759, capítulo 12. AHU cód. 1950.

${ }^{19}$ Embora sejam, efetivamente, um grupo minoritário em relação aos angolas, na primeira metade do século XVIII, os minas chegam a representar quase $30 \%$ da população africana da cidade. Além disso, suas devoções e irmandades indicam ser esse grupo bastante organizado e provido de recursos financeiros. Mariza de Carvalho Soares. Devotos da cor.... ${ }^{20}$ Segundo o marquês, essas capelas, freqüentadas por "pessoas depravadas, e de má vida, e costumes" acontecem "cousas torpes, e indecentes". Por isso seu plano, estabelecido de comum acordo com os irmãos do Rosário, é a demolição das pequenas capelas e a concentração de todas as devoções de pretos na Igreja do Rosário. Requerimento da Irmandade do Rosário ao rei datado de 27.07.1774. AHU. Rio de Janeiro — avulsos — caixa 107 — doc. 31. Agradeço a Maria Fernanda Bicalho a transcrição dessa correspondência.

${ }^{21}$ Essa explicação é dada pelo pintor Jean Baptiste Debret que reside na cidade entre 1816 e 1831, Provavelmente por esse motivo, as folias do Rio de Janeiro não são registradas em suas pranchas, nem nas de outros artistas que visitam a cidade no século XIX. Segundo Debret “...com a presença da Corte no Rio de Janeiro proibiram-se aos pretos as festas fantasiadas extremamente ruidosas a que se entregavam em certas épocas do ano para lembrar a mãe pátria; essa proibição privou-os igualmente de uma cerimônia extremamente tranqüila, embora com fantasias, que haviam introduzido no culto católico. É por esse motivo que somente nas outras províncias do Brasil, se pode observar ainda a eleição anual de um rei, de uma rainha, de um capitão da guarda..." Debret reproduz uma coleta de esmolas na Irmandade do Rosário do Rio Grande do Sul. No Rio de Janeiro, pinta o enterro 
do filho de um rei negro. Na legenda dessa prancha não há qualquer associação entre o filho do rei e as folias que ele afirma não mais festejarem seus santos de devoção na cidade do Rio de Janeiro. Jean Baptiste Debret. Viagem pitoresca e histórica ao Brasil. Notas de Sergio Milliet. São Paulo. Livraria Martins. 1940.

${ }^{22}$ A documentação referente à Igreja de Santo Elesbão e Santa Efigênia é composta por dois conjuntos de fontes. O primeiro diz respeito à documentação própria irmandade (atas e compromissos) pertence ao acervo da própria irmandade (sem qualquer classificação) e também à Biblioteca Nacional do Rio de Janeiro e à Biblioteca Nacional de Lisboa,. O segundo conjunto é composto pelos testamentos pertencentes ao Arquivo da Cúria Metropolitana do Rio de Janeiro, também sem classificação. Recentemente localizei no Arquivo da Cúria uma cópia impressa não datada do compromisso de 1740, com todas as alterações nele acrescidas até o ano de 1767. A ata da Congregação Mahi pertence à Biblioteca Nacional do Rio de Janeiro, BN(MS)9,3,11; a proposta de compromisso da Irmandade de NS dos Remédios pertence à Biblioteca Nacional de Lisboa, AHU/CUcód. 1300 .

${ }^{23}$ É o caso de Antônio Luiz Soares, preto forro mina falecido com bastante idade em 1755 que tendo saído de sua terra com a "idade de sete anos" informa em seu testamento: "declaro que fui nascido em terras de brutos da gentilidade [...] da Costa da Mina e sou nação cabu". Arquivo da Cúria Metropolitana do Rio de Janeiro, Livro de óbitos e testamentos da Freguesia do Santíssimo Sacramento, 1746-1776. fl. 298v. Os cabus são também chamados kabu, gabu ou ngaabu. Alberto da Costa e Silva. A enxada e a lança. A África antes dos portugueses, 2 a edição revista e ampliada. Rio de Janeiro. Nova Fronteira. 1996. pp. 610-612.

${ }^{24}$ Nesse sentido as fontes locais indicam situações mais complexas que as apontadas pelo historiador John Thornton quando argumenta a unidade cultural das confrarias de africanos no Novo Mundo e a formação do que chama de "grupos culturais". Ver John Thornton. Africa and Africans... capítulo 7.

${ }^{25} \mathrm{O}$ mesmo capítulo acrescenta ainda severa punição aos que ousam descumprir essas determinações. A gravidade do ato e a punição a ele atribuída fazem suspeitar da freqüência com que, de modo não esclarecido, os angolas e outros indesejados irmãos impóem sua presença na irmandade. "E o Juiz e mais oficiais e os Irmãos da Mesa que ao contrário fizerem, acabando o ano de sua ocupação não tornarão a servir coisa alguma na dita Irmandade, de que se fará termo pelo Juiz oficial e mais Irmãos de Mesa que logo lhe suceder, destituindo outro sem os ditos Irmãos que admitam os ditos pretos e pretas d'Angola, crioulas ou cabras, tanto homens como mulheres, devolvendo a cada um o que deram de sua entrada, para que fique de nenhum efeito seus assentos de que se fará declaração à margem dos livros deles”. Arquivo da Irmandade de Santo Elesbão e Santa Efigênia, Compromisso da Irmandade (1740) s/ código.

${ }^{26}$ Entre eles os dagomés, mahis, savalus e agolins. É feita ainda menção a um grupo ianno (ou lano) que não pude identificar. BN(MS)9,3,11. A documentação africana cuja nomenclatura mais se aproxima da encontrada no documento da Congregação Mahi por 
mim analisado é a obra do etnólogo Paul Hazoumé, nascido em Porto Novo em 1890, escrita em francês. Doguicimi é considerado o primeiro romance histórico africano. Doguicimi é a esposa do príncipe Toffa, prisioneiro de guerra dos mahi durante o reinado de Ghezo (1818-1858). Paul Hazoumè. Doguicimi. Paris. Maisonneuve et Larose. 1978. ${ }^{27}$ Assinam o primeiro compromisso da irmandade em 1740 quatro irmãos, considerados "fundadores": Francisco Vieira, Antônio Bastos Maia, Francisco das Neves, Antônio Pires dos Santos.

${ }^{28}$ Entre 1744 e 1748 são adquiridos três terrenos em nome da irmandade. Nessas negociaçôes estão envolvidas várias pessoas, dentre elas Manoel dos Santos Martins, Antonio Pires dos Santos e Francisco Gonçalves Nunes, ditos pretos forros e Clemente da Serra preto forro de Cabo Verde. AN — 4o Ofício de Notas. Livro de Notas: 24/2/1744-7/9/ 1744. № 36, p. 109; 4ํㅡㅁ́ㄷㅇ de Notas. Livro de Notas: 20/10/1747-2/5/1748. № 43, p. 140; 1ํㅡ́ㅁio de Notas. Livro de Notas: 10/5/1748-?/11/1748. Caixa 12866. No 115, p. 106. Agradeço a transcrição dos registros a Maurício Abreu.

${ }^{29}$ Candelária é a freguesia portuária, onde se concentram os escravos minas da cidade na primeira metade do século XVIII. Na década de 1750 eles chegam a representar em torno de $50 \%$ da população escrava africana da freguesia, a maior parte deles trabalhando em atividades ligadas ao porto. Ver Mariza de Carvalho Soares. Devotos da cor...

${ }^{30}$ Arquivo da Cúria Metropolitana do Rio de Janeiro, Livro de óbitos e testamentos. Freguesia da Candelária 1797-1809, óbito em 29.07.1803, fl 140v. Agradeço esse testamento a Eduardo Cavalcanti.

${ }^{31} \mathrm{BN}$ (MA) 9,3,11.

${ }^{32}$ Os mahis habitam ao norte do reino do Daomé de quem são tradicionais inimigos. Os únicos trabalhos disponíveis sobre eles são o de Jessie Gaston Mulira. A History of the Mahi Peoples from 1774-1920. A dissertation submitted in partial satisfction of the requirements for the degree of Doctor of Philosophy in History. University of California, 1984; e o de J. A. M. A. R. Bergé. "Étude sur lê pays Mahi”. Bulletin du Comité d'Études Historiques et Scientifiques de l'A O F II (1928). pp. 708-55.

${ }^{33} \mathrm{~A}$ Folia pode sair às ruas várias vezes ao ano, de acordo com os recursos e a vontade dos reis, mas seu principal compromisso é o comparecimento à festa dos oragos da igreja. A Folia se apresenta em trajes especiais cabendo ao rei manto, coroa, cetro e guarda-sol. A mais relevante imagem pictórica das folias da cidade do Rio de Janeiro está em Carlos Julião. (aquarelas por) Riscos iluminados de figurinhos de brancos e negros dos uzos do Rio de Janeiro e Serro do Frio. Introdução histórica e catálogo descritivo por Lygia da Fonseca Fernandes Cunha. Edição comemorativa do quinto centenário do Infante D. Henrique. Rio de Janeiro: Biblioteca Nacional/Ministério da Educação e Cultura. 1960.

${ }^{34}$ Ajudá (capital Glehue), Aladá (capital Aladá) e Daomé (capital Abomé) são três reinos distintos. A disputa entre Aladá e Ajudá ainda não tinha sido resolvida quando o Daomé conquista Aladá em 1724. Com a queda de Aladá, três mil refugiados são enviados a Ajudá, muitos morrem outros tantos são vendidos aos europeus. Não há notícia da chegada de aladás à cidade do Rio de Janeiro, mas eles podem estar entre os minas. No período de 1718 
a 1726 são ao todo batizados 681 adultos minas na Freguesia da Sé da cidade do Rio de Janeiro: 57 em 1718; 64 em 1719; 50 em 1720; 95 em 1721; 107 em 1722; 73 em 1723; 125 em 1724; 79 em 1725 e 31 em 1726. Arquivo da Cúria Metropolitana do Rio de Janeiro, Livro de Batismo de Escravos da Freguesia da Sé, 1718-1726.

35 Segundo Robin Law, os mahis são mencionados como adversários do reino do Daomé pela primeira vez em 1732. Aparecem nos Archives Départementales de la Loire-Atlantique (Nantes, c. 739, Mallet de la Mine, Nantes, 08.01.1732) e na correspondência de João Basílio, administrador da Fortaleza de Ajudá (08. 09.1732), citado por Verger em Fluxo e reflux do tráfico de escravos entre o golfo do Benin e a Bahia de Todos os Santos dos século XVIII a XIX. 3a edição. São Paulo: Editora Corrupio. 1987.p. 154. Os savalus aparecem em 1733 na documentação dos Archives Nationales (Paris) como "sabalours" (c. 6/25, Levet Whydah, 26.08.1733). Robin Law. Slave Coast...

${ }^{36}$ Ambas as expressões são recorrentes na documentação referente aos membros de um mesmo grupo étnico ou de procedência. É interessante o registro de uma cantiga feito por Debret quase um século mais tarde. Segundo ele, "entre os moçambiques as palavras do canto fúnebre são especialmente notáveis pelo seu sentido inteiramente cristão (...). Dou aqui o texto Moçambique em português: "nós estamos chorando o nosso parente, não enxergamos mais; vai em baixo da terra até o dia do juízo, hei de século seculorum amem."

${ }^{37}$ Quero aqui lembrar que o compromisso deve ser entendido como um relato dos acordos e impasses que surgem no interior de um campo de lutas. Se de um lado demonstra as estratégias para controle da Irmandade, por outro aponta para formas de administração das tensões internas. Sobre essa análise ver Mariza de Carvalho Soares. Devotos da cor ..., capítulo V.

${ }^{38}$ A implantação do Império de Santo Elesbão lembra a criação do culto a Mawu no Daomé. Este, entretanto, é tema para outra oportunidade.

${ }^{39}$ Arquivo da Irmandade de Santo Elesbão e Santa Efigênia. Compromisso da Irmandade (1740) capítulo 1 da Folia.

${ }^{40}$ Luiz de Vasconcellos. "Memórias públicas e econômicas da cidade de São Sebastião do Rio de Janeiro para o uso do vice-rei Luiz de Vasconcellos por observação curiosa dos anos de 1779 até o de 1789." Revista do Instituto Histórico e Geográfico Brasileiro. tomo XLVII, parte 1, ano 1884. p. 27.

41 "Regra ou estatutos por modo de hum dialogo onde, se dá noticia das Caridades e Sufragaçoes das Almas que uzam os pretos Minnas, com seus Nacionaes no Estado do Brazil, expecialmente no Rio de Janeiro, por onde se hao de regerem e governarem fora de todo oabuzo gentilico e supersticiozo; composto por Francisco Alves de Souza pretto e natural do Reino de Makim, hum dos mais excelentes e potentados daquêla oriunda Costa da Minna”. BN(MA)9,3,11. Sobre esse documento ver Mariza de Carvalho Soares. "Apreço e imitação no diálogo do gentio convertido" Ipotesi. Revista de estudos literários. V. 4, no 1, jan-jun, 2000. pp.111-123.

${ }^{42} \mathrm{BN}(\mathrm{MA}) 9,3,11$. 
${ }^{43}$ Os mahis estão na irmandade desde os anos de 1740 . No ano de 1755 o rei Pedro da Costa sepulta um filho e o regente Ignácio Gonçalves do Monte, um escravo. A igreja é inaugurada em 1754 e o ano de 1755 corresponde aos primeiros sepultamentos em seu cemitério. Arquivo da Cúria Metropolitana do Rio de Janeiro, Livro de óbitos e testamento da Freguesia da Sé, 1746-1776.

${ }^{44} \mathrm{O}$ fato de ser designado como um "verdadeiro maquino" faz ainda pensar que, entre os assim cotidianamente designados, existiriam alguns mais verdadeiros que outros.

${ }^{45}$ De acordo com a ata da Congregação Mahi, sua morte ocorre no dia 25 de dezembro de 1783. A diferença de dois dias pode ser uma mera confusão ou indicar um tempo pela disputa do morto e de seu legado.

${ }^{46}$ Arquivo da Cúria Metropolitana do Rio de Janeiro, Livro de óbitos e testamentos da Freguesia do Santíssimo Sacramento - 1776-1784.

${ }^{47}$ Esse testamento, encontrado depois da publicação do livro Devotos da cor no qual existe um capítulo sobre a Congregação Mahi, apresenta novas informações além das obtidas através da ata da irmandade que trata da sua morte.

${ }^{48} \mathrm{O}$ prazo normal para essas prestações de conta gira em torno de dois ou três anos, e o dito testamento ainda não foi localizado.

${ }^{49}$ A referência a seu avô como "rei" pode indicar tanto um tipo de poder político centralizado quanto a idéia apresentada por Law de um conjunto de pequenos grupos independentes.

${ }^{50}$ Um Manoel dos Santos Martins está entre os compradores do terreno onde é construída a igreja. O uso do mesmo sobrenome não significa parentesco entre eles e sim a possibilidade de, conforme costume, serem ambos escravos de um mesmo senhor.

${ }^{51} \mathrm{BN}(\mathrm{MA}) 9,3,11$. É praxe em todos os testamentos a viúva aparecer como testamenteira acompanhada de mais um ou dois membros da irmandade que se encarregam de todas as providências a serem tomadas. Esse é um encargo da irmandade e não das organizações de menor porte, existentes no interior da igreja. Apenas a irmandade tem existência jurídica de modo a poder assumir esse tipo de encargo. Isso faz suspeitar que a viúva estaria se aliando à direção da irmandade (controlada pelos dagomés) em oposição ao grupo da Congregação Mahi até então governada por seu marido. Daí sua pretensão de ser a imperatriz da Costa da Mina, cargo que só pode ser atribuído à mulher que acompanha o Imperador da irmandade e não a simples rainhas de folias nacionais.

52 Sobre recursos feitos às autoridades régias e ao próprio monarca ver A. J. R. RussellWood. "Acts of grace': Portuguese monarchs and their subjects of African descent in eighteenth-century Brazil”. Journal of American Studies 32, 307-332. Cambridge University Press. 2000.

53 Por volta do ano de 1758, Tegbesu manda decapitar o agau do exército daomeano sob suspeita de pretender deserdar para o país mahi. Mas ao mesmo tempo, a esposa preferida de Tegbesu é uma mulher mahi, que vem a ser a mãe de Kpengla, seu sucessor no trono do reino. Robin Law. The slave coast ...p 328. Sobre esses laços familiares ver Archibald 
Dalzel. The history of Dahomy an inland kingdom of Africa. Compiled from authentic memoires by Archibald Dalzel. A second printing with a new introduction by J. D. Fage. Frank Cass \& Co. Ltd. 1967. pp. 76, 165, 192.

${ }^{54}$ Archibald Dalzel. The history of Dahomy... p. 214.

${ }^{55}$ Embora ainda não seja possível fornecer números exatos, os testamentos mostram que os minas, individualmente ou em grupo reúnem o maior patrimônio entre os africanos aforriados. Sobre isso ver trabalhos recentes de Sheila de Castro Faria. "Mulheres forras riqueza e estigma social”. Tempo, vol.5, no 9, jul/2000. pp. 65-92.

${ }^{56}$ É oportuno lembrar que a primeira embaixada do Daomé ao Brasil é enviada por Tegbesu e chega à cidade de Salvador, então capital da colônia do Brasil em 1750. Pierre Verger. Fluxo e refluxo... pp. 257-263.

${ }^{57}$ Livro de batismo de livres — Freguesia da Sé (1744-1761), 05.05.1745.

58 Ao longo do século XIX se generaliza o uso da palavra crioulo para todos os afrodescendentes escravos, forros ou livres nascidos no âmbito da sociedade colonial e depois imperial.

59 Se as tradições são apagadas pelo tempo, pela ocidentalização ou pela mestiçagem isso ocorre como resultado de um processo extremamente mais complexo e lento que o da vida de uma geração. Faço aqui uma referência ao debate que deriva dos trabalhos de Sidney W. Mintz e Richard Price. The birth of African-American culture: an anthropological perspective. (1 à edição 1976). Boston. 1992.

${ }^{60} \mathrm{BN}(\mathrm{MS}) 9,3,11$.

\section{Resumo}

$O$ artigo analisa a especificidade das formas de organização da geração de escravos africanos vindos da África Ocidental para a cidade do Rio de Janeiro no século XVIII. A autora mostra como esses africanos se reorganizam no interior das irmandades católicas destinadas a homens pretos e como garantem espaços de organização étnica e reprodução do grupo.

\section{Abstract}

The article concerns on the special condition of the enslaved West African born peoples in Rio de Janeiro city, during the $18^{\text {th }}$ century. The author shows how these Africans make use of their ethnic identity as a base to the catholic black brotherhoods where they organize themselves and keep the group together. 